\title{
The Control of Walking Movements in the Leg of the Rock Lobster
}

\author{
H. Cruse ${ }^{\star}$, F. Clarac ${ }^{\star \star}$, and C. Chasserat \\ Laboratoire de Neurobiologie comparée, F-33120 Arcachon, France
}

\begin{abstract}
Experiments with rock lobsters walking on a treadmill were undertaken to obtain information upon the system controlling the movement of the legs. Results show that the position of the leg is an important parameter affecting the cyclic movement of the walking leg. Stepping can be interrupted when the geometrical conditions for terminating either a return stroke or a power stroke are not fullfilled. 2. The mean value of anterior and posterior extreme positions (AEP and PEP respectively) of the walking legs do not depend on the walking speed (Fig. 1). 3. When one leg is isolated from the other walking legs by placing it on a platform the AEPs and PEPs of the other legs show a broader distribution compared to controls (Figs. 2 and 3). 4. Force measurements (Fig. 4) are in agreement with the hypothesis that the movement of the leg is controlled by a position servomechanism. 5 . When one leg stands on a stationary force transducer this leg develops forces which oscillate with the step rhythm of the other legs (Fig. 5). 6. A posteriorly directed influence is found, by which the return stroke of a leg can be started when the anterior leg performs a backward directed movement. 7. Results are compared with those obtained from stick insects. The systems controlling the movement of the individual leg are similar in both, lobster and stick insect but the influences between the legs seem to be considerably different.
\end{abstract}

\section{Introduction}

The purpose of this investigation is to obtain information upon the construction of the system controlling the walking movements of the legs in a rock lobster (Jasus lalandii, Decapod, Crustacea). Leg reflexes have

\footnotetext{
* Supported by DAAD and DFG Cr. 58/2. Present address: Fakultät Biologie, Postfach 8640, D-4800 Bielefeld, Federal Republic of Germany

** Supported by INSERM ATP 80.79 .112
}

been intensively investigated using restrained, nonwalking animals (intraleg reflexes: e.g. Ayers and Davis, 1977; review interleg reflexes: Clarac, 1981). However, since a change of the internal state of the animal may also alter the way it responds to sensory input, our knowledge of this system should be supported by experiments upon the actively walking animal. Relevant information can be obtained both through investigating the intact and undisturbed walking animal and through observing the reaction of the system to experimentally produced disturbances. In describing the movement of a walking leg, earlier authors considered mainly temporal parameters such as duration of power stroke and return stroke or in sum, the step period. Such geometrical parameters as anterior extreme position (AEP), posterior extreme position (PEP) and stride length have received little or no attention and will be investigated in this paper.

In the experiments described here the animals walk on a treadmill. As we have shown in earlier papers (Clarac and Cruse, 1982), animals in this situation show normal although somewhat stereotyped walking behaviour. This setup has the experimental advantages that the walking speed can be controlled by the experimentor and that analysis of the movement of a leg is much easier when the body of the animal is fixed (Clarac and Chasserat, 1983). In addition, as with insects walking on a treadwheel, one leg of the walking animal can be placed on a platform fixed beside the treadmill.

\section{Methods}

Adult rock lobsters (Jasus lalandii) with a mean weight of $400-500 \mathrm{~g}$ (measured in air; the equivalent weight in water is $\sim 50 \mathrm{~g}$ ) were used. Only forward walking was investigated. The animals were tethered at the carapace and walked on a motor driven treadmill. The weight of the tether was counter-balanced so that the 


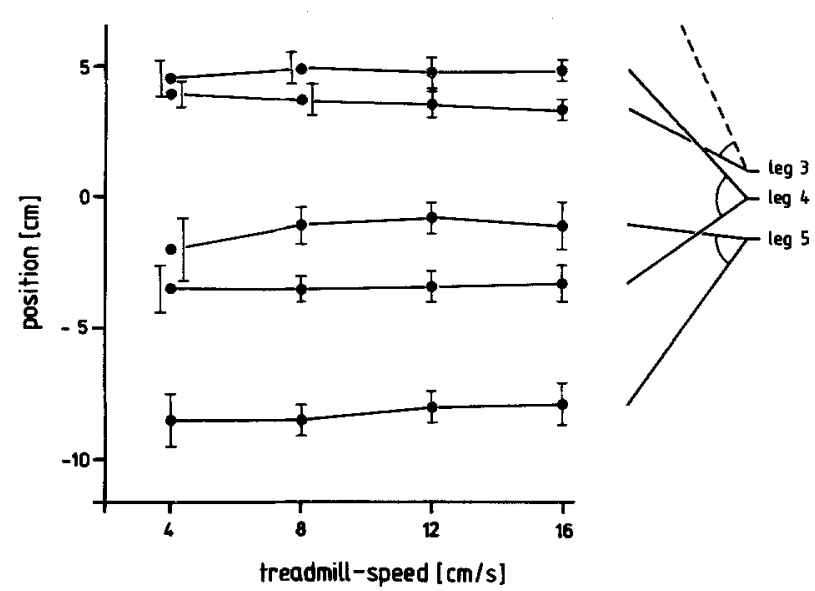

Fig. 1. Mean values and standard deviations of extreme positions of leg 3,4 , and 5 for different speeds of the treadmill. Position of coxae and approximate range of leg movement is shown on the right hand side of the diagram. AEP of leg 3 has not been measured. Values from 4 animals. Each mean value is calculated from at least 191 steps

Table 1. Position (in $\mathrm{cm}$ ) of AEP and PEP of leg 3,4 and 5, when the leg stands on the platform being moved slowly in backward direction. For each position mean values, standard deviation and sample size are given. The middle of coxa of leg 4 is used as origin. Positive values in anterior direction. Results from 3 animals

\begin{tabular}{|c|c|c|c|c|}
\hline & & Control & $\begin{array}{l}\text { Leg on } \\
\text { moving platform }\end{array}$ & $\begin{array}{l}\text { Difference } \\
\text { from control }\end{array}$ \\
\hline \multirow[t]{2}{*}{ Leg 3} & $\mathrm{AEP}$ & $\begin{array}{r}11.2 \\
+\quad 0.3 \\
179.0\end{array}$ & $\begin{array}{r}9.8 \\
+\quad 0.8 \\
113.0\end{array}$ & -1.4 \\
\hline & PEP & $\begin{array}{r}4.3 \\
\pm \quad 0.5 \\
206.0\end{array}$ & $\begin{array}{r}5.5 \\
\pm \quad 2.6 \\
127.0\end{array}$ & 1.2 \\
\hline \multirow[t]{2}{*}{ Leg 4} & $\mathrm{AEP}$ & $\begin{array}{r}5.1 \\
\pm \quad 0.6 \\
206.0\end{array}$ & $\begin{array}{r}2.8 \\
+\quad 2.4 \\
131.0\end{array}$ & -2.3 \\
\hline & PEP & $\begin{array}{r}4.6 \\
\pm \quad 0.6 \\
204.0\end{array}$ & $\begin{array}{r}4.6 \\
\pm \quad 2.8 \\
140.0\end{array}$ & 0 \\
\hline \multirow[t]{2}{*}{$\operatorname{Leg} 5$} & AEP & $\begin{array}{rr}-\quad 1.0 \\
\pm \quad 0.5 \\
193.0\end{array}$ & $\begin{array}{r}-\quad 3.0 \\
\pm \quad 1.1 \\
111.0\end{array}$ & -2.0 \\
\hline & PEP & $\begin{array}{r}-9.3 \\
\pm \quad 0.5 \\
237.0\end{array}$ & $\begin{array}{lr}- & 10.4 \\
\pm \quad & 1.4 \\
140.0\end{array}$ & -1.1 \\
\hline
\end{tabular}

animal supported only its own weight (for details see Chasserat and Clarac, 1980). Anterior extreme position (AEP) and posterior extreme position (PEP) of legs (legs 3, 4, and 5) were measured using a ruler fixed outside the aquarium parallel to the longitudinal axis of the body. Then, one leg was viewed from the side and the positions where the leg lifted off the ground (PEP) and where it again touched the ground (AEP) were recorded to the nearest $0.5 \mathrm{~cm}$. As the absolute values of the extreme positions showed considerable individual variation and as the values of consecutive steps are not independent of one another, a rough significance criterion is used: two mean values are only considered as being significantly different when their difference is greater than the largest of the two standard deviations.

In some experiments on leg 4 and leg 5 the forces with which the leg acts on the ground were measured. For this purpose a force transducer (strain gauge) was fixed on a plastic tube which was pushed over the dactylo- and propodite. Then the animal walked on the force transducer instead of the dactylo-podite (for details see Clarac and Cruse, 1982). The force component measured by this transducer (force transducer I in Clarac and Cruse, 1982) mainly corresponds to the force developed in the $\mathrm{T}-\mathrm{C}$ joint. Forces pushing the body forward are labeled positive. In another experiment, when one leg was placed on a small, stationary platform $(10 \times 15 \mathrm{~mm})$ the force produced by the leg was measured by a force transducer built into the platform in the following way: It measured the force component parallel to the longitudinal axis of the body. The speed of the treadmill was $8 \mathrm{~cm} / \mathrm{s}$ in all experiments when not stated otherwise. This speed was chosen because it corresponds to the normal speed of the free walking animal.

\section{Results \\ Position Measurements}

In the first experiment, for 4 animals the PEP of leg 3 , and both AEP and PEP of legs 4 and 5 were measured for different speeds of the treadmill. The results are shown in Fig. 1. Position is measured relative to the body axis with the middle of the coxa of leg 4 as origin and anterior as positive. The values for a given animal and a given speed show a very small scatter. The mean values change considerably from animal to animal due to different length of the legs or other individual differences. In order to obtain a value for the standard deviation which is not influenced by these individual differences, the standard deviation is calculated after normalization of the mean values for each extreme value of each animal (the final mean values are not influenced by the procedure). Despite the fact that some animals did show a slight change of AEP and PEP depending upon the imposed speed, taking all experiments together, the results show that the extreme positions are mainly independent of walking speed for the speeds tested. However, for the slowest speed the overlap between leg 3 and 4 and between leg 4 and 5 seems to be somewhat smaller indicating a smaller step amplitude.

In the second experiment animals walked on the treadmill with a speed of $8 \mathrm{~cm} / \mathrm{s}$ and leg 4 was placed 

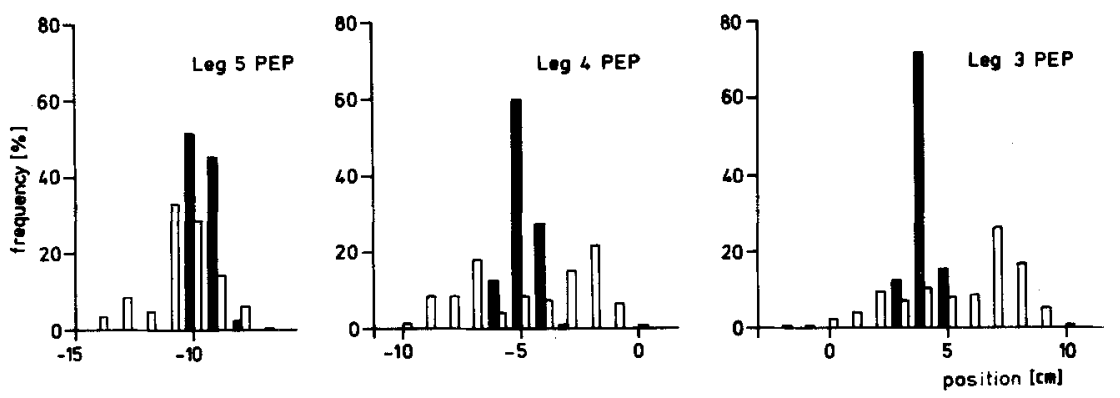

Fig. 2. Distribution of PEP values of leg 3, 4, and 5 , when the leg stands on a platform moving slowly in backward direction. (white columns). Distribution of controls are shown as black columns

Table 2. Mean values of AEP and PEP of leg 3, 4, and 5, when one of these legs is standing on a fixed platform. For further explanations see Table 1

\begin{tabular}{|c|c|c|c|c|c|c|c|}
\hline & & $\begin{array}{l}\text { Leg } 3 \text { on } \\
\text { fixed platform }\end{array}$ & $\begin{array}{l}\text { Difference } \\
\text { from control }\end{array}$ & $\begin{array}{l}\text { Leg } 4 \text { on } \\
\text { fixed platform }\end{array}$ & $\begin{array}{l}\text { Difference } \\
\text { from control }\end{array}$ & $\begin{array}{l}\text { Leg } 5 \text { on } \\
\text { fixed platform }\end{array}$ & $\begin{array}{l}\text { Difference } \\
\text { from control }\end{array}$ \\
\hline Leg 3 & AEP & & & $\begin{array}{r}11.5 \\
+\quad 1.4 \\
122.0\end{array}$ & 0.3 & $\begin{array}{r}10.9 \\
\pm \quad 1.3 \\
142.0\end{array}$ & -0.3 \\
\hline & PEP & & & $\begin{array}{r}4.9 \\
+\quad 2.3 \\
155.0\end{array}$ & 0.6 & $\begin{array}{r}3.6 \\
+\quad 0.8 \\
122.0\end{array}$ & -0.7 \\
\hline Leg 4 & AEP & $\begin{array}{r}4.8 \\
\pm \quad 1.5 \\
139.0\end{array}$ & -0.3 & & & $\begin{array}{r}4.4 \\
\pm \quad 2.0 \\
132.0\end{array}$ & -0.7 \\
\hline & PEP & $\begin{array}{r}-4.2 \\
\pm \quad 1.3 \\
138.0\end{array}$ & 0.4 & & & $\begin{array}{r}5.1 \\
\pm \quad 2.3 \\
162.0\end{array}$ & -0.5 \\
\hline Leg 5 & AEP & $\begin{array}{r}-\quad 1.9 \\
\pm \quad 1.2 \\
45.0\end{array}$ & -0.9 & $\begin{array}{r}1.5 \\
\pm \quad 1.4 \\
183.0\end{array}$ & -0.5 & & \\
\hline & PEP & $\begin{array}{r}9.4 \\
+\quad 0.5 \\
+\quad 45.0\end{array}$ & -0.1 & $\begin{array}{r}-\quad 9.1 \\
\pm \quad 0.9 \\
140.0\end{array}$ & 0.2 & & \\
\hline
\end{tabular}

on a small platform directly above the surface of the treadmill belt. When this platform was positioned within the range of the normal movement of the leg, leg 4 remained standing on the platform whilst the other legs were walking. Immediately after the leg was placed on the platform, the other legs sometimes stopped walking for several seconds but then resumed walking. This experiment was performed with legs 3,4 , and 5. This result shows that the cyclic movement of a walking leg can be interrupted during the power stroke; this was earlier shown to be the case in the stick insect Carausius morosus (Wendler, 1964).

The experimental situation was then changed so that the platform was not fixed but was slowly moved backwards ( 24 times slower than the other legs walking on the treadmill). Under these conditions the leg eventually lifted off the platform; PEP and AEP were recorded. The results for leg 3,4 , and 5 are shown in Table 1. Mean values for AEP and PEP were normalized, for each animal by subtracting the means for the leg on the moving platform from those obtained during normal walking. The results show that the AEP of all three legs are shifted backwards. The value for leg 4 is shifted backwards as forward movement of leg 4 is often mechanically impeded because of leg 3 being in posterior position. The same may be due to AEP of leg 5. No changes in PEP values are significant according to our significance criterion. However, the scatter for all three legs is much greater than that of normal walking legs (Fig. 2). For legs 3 and 4, the results differ greatly from a normal distribution and seem to be bimodal. This means that the leg either is lifted in front of the normal PEP or is moved backward far behind the normal PEP. Observation during the experiment suggested that this bimodality was related to two different levels of force generated by the leg. When the leg pressed more strongly against the platform, it retracted farther to the rear. In the different animals either both types of behaviour occur or the one or the other type was dominant during the measurements. There seems to exist a gradient among the three legs: for leg 3 anteriorly shifted PEP's are most frequent, for leg 5, only posteriorly shifted PEP's occur, while for leg 4 both types occur with the same 

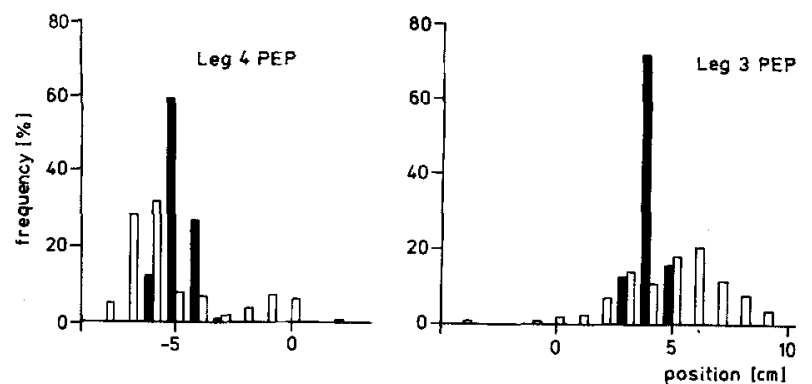

Fig. 3. Distribution of PEP values of $\operatorname{leg} 3$ and 4, when the next posterior leg is standing on a fixed platform (white columns). Distribution of controls are shown as black columns

frequency. Although the differences found between leg 3 and leg 4 may be due to the particular individuals studied, qualitative observation of other animals revealed the same effect.

In the third experiment one of the three legs 3,4 or 5 was placed on the fixed platform and the extreme values of the other walking legs were measured. Research on stick insects in this experimental situation has shown that the next posterior leg changes its AEP in order to reach the position of the leg on the platform (Cruse, 1979), whereas there is no effect upon the PEP of any of the walking legs (Cruse and Epstein, 1982). In lobsters (Table 2) no significant changes in AEP or PEP on the part of the legs behind the leg on the platform are found except for a general enlargement of the standard deviations by a factor of 2 to 3 . However, the standard deviations of the extreme positions of the leg in front of that on the platform are increased even more; this is particularly true for the PEP. Therefore,
Fig. 3 shows the distribution of PEP values for legs 3 and 4 when the next posterior leg (legs 4 and 5 respectively) is standing on the fixed platform.

When leg 5 is on the platform the PEP of leg 4 is clearly shifted backwards although some PEP's in front of the normal PEP also occur. As was the case for leg 3 on the moving platform, when leg 4 is on the platform, the PEP of leg 3 is more often shifted in anterior direction, although also backwards shifted PEP's occur.

In the fourth experimental series, one leg (either 4 or 5) was tied up with a rubber band instead of being placed on the fixed platform, so that it could not move downwards to touch the ground (Table 3a) or one of the legs (either 4 or 5 ) was autotomized (Table $3 b$ ). When leg 4 is tied up, it either remains immobile or moves the $\mathrm{M}-\mathrm{C}$ joint at the step frequency of the other legs. Coordination between legs 3 and 5 seems to be very variable. When $\operatorname{leg} 4$ is autotomized, the stump moves in phase with leg 3 . Legs 3 and 5 move out of phase (Clarac, 1981). This means that with respect to the temporal parameters the results for both situations are different. However, for the geometrical parameters, the global effect is the same. In both situations no significant or at most significant, but weakly significant backward shifts are found in leg 5 (Table 3). All other extreme positions show significant backward shifts; the largest change is in PEP of leg 3 when leg 4 is tied up or autotomized. (The AEP of leg 3 was investigated only in one animal where no changes were found).

Table 3a and b. Mean values of AEP and PEP of leg 3,4 and 5, when leg 4 or leg 5 is a tied up or $\mathbf{b}$ autotomized. For further explanations see Table 1

\begin{tabular}{|c|c|c|c|c|c|c|c|c|c|}
\hline a & & $\begin{array}{l}\text { Leg } 4 \\
\text { tied up }\end{array}$ & $\begin{array}{l}\text { Difference } \\
\text { from control }\end{array}$ & $\begin{array}{l}\text { Leg } 5 \\
\text { tied up }\end{array}$ & $\begin{array}{l}\text { Difference } \\
\text { from control }\end{array}$ & $\begin{array}{l}\text { b } \\
\text { Leg } 4 \\
\text { autotomized }\end{array}$ & $\begin{array}{l}\text { Difference } \\
\text { from control }\end{array}$ & $\begin{array}{l}\text { Leg } 5 \\
\text { autotomized }\end{array}$ & $\begin{array}{l}\text { Difference } \\
\text { from control }\end{array}$ \\
\hline \multirow[t]{2}{*}{$\operatorname{Leg} 3$} & AEP & & & $\begin{array}{r}11.2 \\
\pm \quad 0.5 \\
44.0\end{array}$ & 0 & & & & \\
\hline & PEP & $\begin{array}{r}1.6 \\
\pm \quad 0.8 \\
235.0\end{array}$ & -2.7 & $\begin{array}{r}3.4 \\
\pm \quad 0.3 \\
159.0\end{array}$ & -0.9 & $\begin{array}{r}2.0 \\
\pm \quad 0.8 \\
209.0\end{array}$ & -2.3 & $\begin{array}{r}2.4 \\
\pm \quad 0.8 \\
120.0\end{array}$ & -1.9 \\
\hline \multirow[t]{2}{*}{ Leg 4} & AEP & & & $\begin{array}{r}3.8 \\
+\quad 0.5 \\
168.0\end{array}$ & -1.3 & & & $\begin{array}{r}3.6 \\
\pm \quad 0.9 \\
147.0\end{array}$ & -1.5 \\
\hline & PEP & & & $\begin{array}{r}-\quad 5.6 \\
\pm \quad 0.8 \\
161.0\end{array}$ & -1.0 & & & $\begin{array}{r}-\quad 6.3 \\
\pm \quad 0.9 \\
109.0\end{array}$ & -1.7 \\
\hline \multirow[t]{2}{*}{ Leg 5} & AEP & $\begin{array}{r}1.1 \\
\pm \quad 0.8 \\
214.0\end{array}$ & -0.1 & & & $\begin{array}{r}0.2 \\
\pm \quad 0.6 \\
223.0\end{array}$ & -0.8 & & \\
\hline & PEP & $\begin{array}{r}-\quad 9.6 \\
\pm \quad 0.7 \\
224.0\end{array}$ & -0.3 & & & $\begin{array}{r}9.2 \\
\pm \quad 0.7 \\
208.0\end{array}$ & -0.1 & & \\
\hline
\end{tabular}




\section{Force Measurements}

A second series of experiments measured the forces which are developed by the legs. In the first experiment a force transducer was attached only to leg 4 . When the animal walks on the treadmill, and the treadmill is suddenly stopped either during the power stroke (Fig. 4a) or during a return stroke (Fig. 4b), the profile of forces shows no difference from that of a normal step. However, then the force value does not fall down to zero but remains high until the treadmill is again started. The force remains high even when the pause lasts $30 \mathrm{~s}$ or more; in contrast, for stick insects under these conditions the excitation of the retractor coxae muscle decreases to zero within $1 \mathrm{~s}$ (Graham, in prep.). Occasionally, a lobster produces negative force values (trying to decelerate the speed of the treadmill) but even then stopping the treadmill elicited the development of positive forces (Fig. 4c).

For stick insects in which the leg stands on a platform while the other legs walk freely, the standing leg exerts a force on the platform which oscillates in the rhythm of the walking legs (Cruse and Saxler, 1980). Therefore, in the second experiment a force transducer was attached to leg 4 and this leg was placed on a stationary platform. A second force transducer was attached to the ipsilateral leg 5 in order to measure the timing of power and return strokes by this leg. In the rock lobster, as for the stick insect, the standing leg 4 showed a force oscillation in the walking rhythm of leg 5 (Fig. 5a). Figure $5 b$ shows the frequency of occurrence of a force maximum (f. max.) and a force minimum (f. min.) in leg 4 relative to the cycle movement of leg 5 . Phase 0 marks the beginning of the power stroke of leg 5 . The power stroke occupies on average $60 \%$ of the step period with a standard deviation of $\pm 8 \%$. The return stroke is symbolized by a black bar below the abscissa. As can be seen, a force minimum in the standing leg occurs during the power stroke of leg 5. Assuming, that a force maximum in leg 4 corresponds to a "virtual" power stroke, this can be described as an alternative coordination between both legs.

We also tried to measure the phase relation between leg 4 when standing on the platform and the walking leg 3 . There appeared to be a weak in-phase coordination but the mean phase was much less clear. In contrast to leg 5 , leg 4 was mechanically disturbed by the platform of leg 4 and therefore often made irregular movements. Coordination of leg 3 may be generally weaker: in backward walking leg 3 often is not very well coordinated with leg 4 (Chasserat and Clarac, 1980). The same results were obtained when the force transducer was built into the platform instead of being fixed at the leg. The force oscillations were
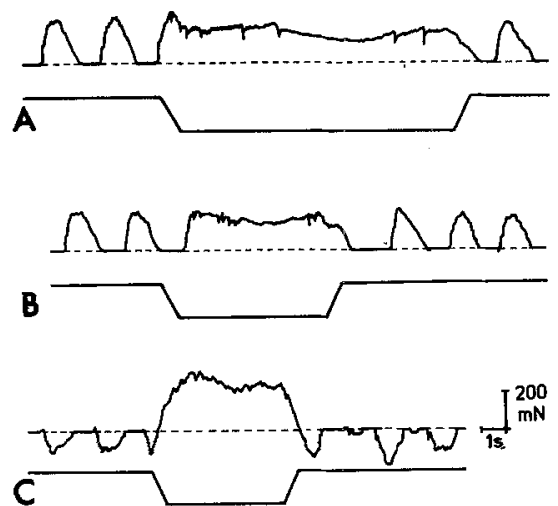

Fig. 4A-C. Upper trace: forces developed by leg 4. Positive values represent forces in posterior direction. Lower trace : the speed of the treadmill varies between $6 \mathrm{~cm} / \mathrm{s}$ (upper position) and zero (lower position)

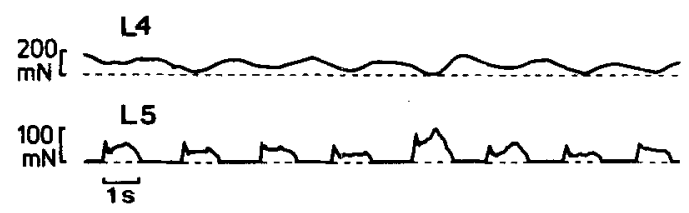

A
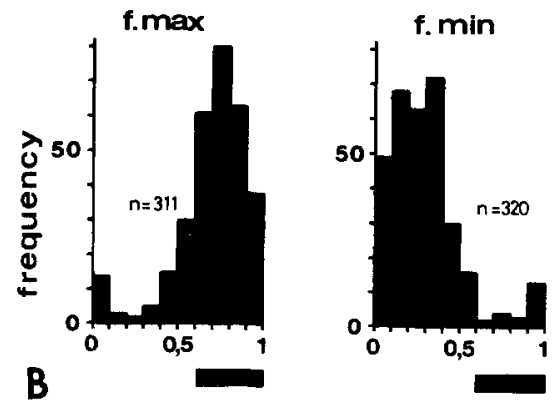

Fig. 5. a Forces developed by leg 4 standing on a fixed platform and leg 5 walking on the treadmill. Positive values represent forces in posterior direction. $\mathbf{b}$ The frequency of occurrence of force maximum (f. max.) and force minimum (f. min.) of leg 4 relative to the cyclic movement of leg 5 . The black bar shows the return stroke of leg 5

also found when the body of the animal was fixed rigidly in order to avoid force transduction through the body from the other legs. Qualitative observation showed that these force oscillations occur also in backward walking.

In the rock lobster the coxae of the legs lie very near together, which might suggest that the force oscillations measured here are produced by mechanical influence from leg 5 to leg 4 . However, this mechanism would produce just the opposite phase relation to those actually measured. In a further control experiment the identical force oscillation in the standing leg 4 were found when leg 5 was mechanically constrained to make walking movements only in the posterior half of its normal range of movement. In leg 4 the $d$-c-value 
of the forces was measured when the leg is standing on the platform. The results are qualitatively the same as obtained in stick insects (Cruse, in prep.) as the d-cvalue of the force is high $(\sim 300 \mathrm{mN})$ when the platform is in the anterior part of the normal range of movement of the leg (near AEP) and is small $(0-50 \mathrm{mN})$ when the platform is in the posterior part (near PEP).

\section{Discussion}

The main intent of this research is to obtain information on those parameters that are important in controlling the movements of the legs of a walking animal. Earlier papers showed the importance of temporal parameters (e.g. MacMillan, 1975, Chasserat and Clarac, 1980). Therefore our attention was directed to the question of whether geometrical parameters may play a role. Grote (1981) described differences in stride length between animals walking in the air and under water. Thus it is very probable that stride length depends upon load but this change might also be produced by other factors. In his experiments the condition for all legs was changed in more or less the same way. In our experiments we tried to change the situation for individual legs separately.

The results can be separated in two groups, one concerning the control of movement of the individual leg and the other concerning the coupling between different legs.

\section{Control of the Individual Leg}

Cyclic movement of the walking leg seems to depend strongly on geometrical conditions as AEP and PEP in forward walking are largely independent on the walking speed and as the cyclic movement can deliberately be interrupted during the power stroke by placing the leg on a platform fixed relative to the body.

Observation showed that the cycle could also be interrupted during the return stroke by holding a stick vertically in front of the leg. The leg continues protraction movement until the stick is moved forward allowing the leg movement in its anterior range.

These results show that the pattern generator producing the cylic movement depends on geometrical conditions which have to be fullfilled to enable switching from power stroke to return stroke and vice versa. Corresponding results are also found in jumping spiders (Land, 1972) and in stick insects (Cruse and Epstein, 1982). The strong increase of the standard deviation of PEP in several experiments indicates that temporal coordinating commands influence mainly the
PEP, much more than the AEP of a leg. This is in agreement with previous results for rock lobsters (Clarac, 1981) and for stick insects (Graham and Cruse, 1981).

Although rock lobsters show resistance reflexes to passive movement of the leg (Ayers and Davis, 1977; Barnes, 1977; Clarac et al., 1978), when walking on the motor driven treadmill the legs normally do not oppose this movement but try to support it (Fig. 4a and b). Two hypotheses have been suggested to explain this behaviour. (I): During walking mode the negative feedback systems change to positive feedback. Such a reversal from resistance reflex to assistance reflex was found by several authors (Bässler, 1976; Di Caprio and Clarac, 1981). (II): The resistance reflex is part of a servo-mechanism. No switch from negative to positive feedback is necessary. When the reference input representing the "desired" leg position takes on a value posterior to the real leg position, the resulting error signal increases the force directed posteriorly.

Is it possible to find arguments against the one or the other hypothesis by means of the experimental results? The result presented in Fig. 4a (the treadmill stops during the power stroke) can be described by both hypotheses. Results shown in Fig. $4 \mathrm{c}$ demonstrate that sometimes the leg can oppose the movement of the treadmill despite our impression that the animal was walking normally. According to hypothesis I, one has to assume that in this situation the resistance reflex is operating although the animal is in walking mode. Furthermore, one has to assume that when the treadmill is stopped the assistance reflex is switched on, and when the treadmill is started it is switched off again. The results shown in Fig. 4c can however be described by the servomechanism hypothesis with the single assumption that the animal wants to walk slower than the given speed of the treadmill. Then during the power stroke the "desired" leg position moves backward more slowly than the actual leg position producing a negative error signal and thus negative forces. When the treadmill stops during such a power stroke, the "desired" position overtakes the actual position, leading to a positive error signal and positive forces. This agrees with the results shown in Fig. 4c. Furthermore, if this hypothesis were true, then in such a situation (the animal walks forward but with negative forces) slowing down the treadmill speed should lead to positive force values; such a change was observed in several instances. Figure $4 \mathrm{~b}$ shows that the force value developed by the leg increases as in the normal step when the treadmill is stopped before the leg touches the ground to begin the power stroke. This result is difficult to explain by an assistance reflex as in this situation no stimulus exists to which the reflex could respond. No such contradiction occurs for 
hypothesis II. In fact, the increase of the force could then be considered as a measure of the time course of the reference input value of the servo-system.

When walking on the treadmill the maximum force values decrease with increasing treadmill speed (Clarac and Cruse, 1982). Under the hypothesis of the positive feedback one normally would expect the opposite. This result, however, easily fits the servomechanism hypothesis. The faster the real speed of the leg the smaller is the difference between actual and "desired" leg position. A smaller error signal results in smaller force values.

Under hypothesis II when a leg stands on a fixed platform one would expect the reference input of the servo-system corresponding to a value near PEP as this is the "desired" position. Therefore one should expect high $\mathrm{d}-\mathrm{c}$-force values when the platform is near the AEP and small d-c-force values when the leg on the platform is near the PEP. Qualitatively, this result was obtained here and agrees with findings for stick insect (Cruse, in prep.)

Thus considering the control of the walking movements of the leg the following hypothesis is supported: There exists an internally represented anterior and posterior threshold position at which the leg changes its mode from power stroke to return stroke or vice versa. The actual level of the posterior threshold value might be influenced by temporal coordinating commands. During the power stroke the leg movement is controlled by a position-controlling servomechanism. This model has been applied to summarize corresponding experimental results obtained from stick insects (Cruse, 1980a and b).

Comparing the systems controlling the movement of the individual leg in lobsters and stick insects, much similarity is evident. However, there are also some differences. For instance, a walking lobster can hold one leg at the PEP for a second or more as if waiting for a signal to start the return stroke. Also in individual steps the duration of the return stroke can be changed in order to reach proper coordination (Clarac, 1981). Both results are not observed to this extent in insects. After stopping the treadmill the lobster continues to develop force against the ground whereas in stick insect this force disappears after some seconds.

\section{Influences Between Legs}

Earlier results indicate that interleg coordination is clearly stronger in insects than in crustacea. This difference is evident in two ways: I) The number of legs used by crustacea for walking can be very variable. Sometimes all five pairs are used, sometimes only four or three pairs. In the ghost crab walking can be performed by only two pairs (Burrows and Hoyle,
1973). II) The phase between two walking legs in crustacea can be more variable than in insects. Relative coordination is quite frequent in lobsters (Chasserat and Clarac, 1980). We found corresponding differences in the behaviour of the leg on the slowly moved platform: In insects the leg lifts off the platform before it reaches the normal PEP but in proper temporal coordination with the other legs (Cruse and Epstein, 1982). In the lobster the leg at times seems to be uncoupled from the other legs and often lifts off the platform at a completely unnatural phase of stepping compared by the other legs. This is particularly true when the leg lifts off far behind the normal PEP. This indicates that in this situation the start of return stroke is mainly controlled by the geometrical parameters of the leg itself. Temporal signals probably active in normal walking are less important.

Another result shows that in the lobster the individual legs are less strongly coupled than in insects. In the lobster the AEP of a leg does not follow the position of the next anterior leg when this stands on the fixed platform. Perhaps accurate placement of legs is more important for insects climbing on thin branches than for lobsters living under water and walking on more solid surface.

However, interleg coupling signals do exist. The force oscillations of the leg standing on the platform and the rhythmic movements in the $\mathrm{M}-\mathrm{C}$-joint of a tied leg show that coordinating influences are still present. The experiments do not reveal where these influences come from. In electrophysiological measurements Clarac (1981) showed both forward and backward directed influences. The force oscillations might possibly be derived from forward directed influences described by Clarac which produce alternating coordination.

The following observation shows a backward directed influence. When leg 4 was placed on the platform, leg 5 very often stopped at its PEP for one or more step cycles. If the platform together with leg 4 was moved backwards by hand about 1 or $2 \mathrm{~cm}, \operatorname{leg} 5$ immediately started its return stroke. In this way, the return stroke of leg 5 could be elicited during the posterior part of its power stroke, but never in the anterior part.

An effect probably derived from the same influence could be observed in the following way. When leg 3 was placed on the fixed platform, then leg 4 sometimes made very short steps. In this case leg 5 remained in a stretched position near its normal PEP and started a return stroke only when leg 4 performed a step with a large amplitude.

When a leg of the walking animal is placed on the fixed platform the standard deviation of the PEP of the 
next anterior leg is enlarged and, particularly in leg 4, is often shifted backwards. A backward shift of the extreme positions of the anterior leg is also found when the leg was tied up or autotomized. Corresponding results have been found in free walking insects with one leg amputated (Hughes, 1957; Bässler, 1972). One might speculate that this change is the result of a "tonic" mechanism which shifts the range of movement of a leg in a posterior direction when the next posterior leg cannot take part in normal walking. The biological sense of this mechanism might be to replace this non operating leg. Consequently one might speculate that the enlarged scatter of PEP values found when the leg stands on the moved platform (Fig. 2, leg 3, and 4) might result from a superposition of this "tonic" effect and a second "phasic" effect which results from temporal coordinating influences from other legs. As the leg on the platform moves slowly such a temporal command normally occurs too "early" and therefore could initiate a return stroke somewhat before the normal PEP. Depending on the internal state of the animal the one or the other effect might dominate and so produce the broad and sometimes bimodal distributions.

For stick insects walking on a treadwheel with one leg standing on a fixed platform no changes are found in AEP and PEP of the other legs. (Cruse and Epstein, 1982). In those experiments the distance between body and treadwheel was fixed, therefore, the other legs were not subjected to changes in vertical load. This is not the case for experiments with free walking animals or for our experiments in which the lobster supported its own weight. Thus the changes of PEP and AEP of individual legs measured here might at least partly be produced by load changes acting on the leg itself rather than by signals from other legs.

In conclusion one can say that on the basis of our results the system controlling the movement of the individual leg seems to be relatively similar in insects and crustacea. However, interleg coupling is weaker in crustacea. Thus the same mechanisms might exist but are less strong in crustacea. This might not only be due to the fact that lobsters can walk in very different directions, but also to the fact that even in straight forward walking these animals can select different sets of legs for use in walking. In only one case did we find an obvious difference between insects and crustacea. In the latter AEP is not dependent of the PEP of the next anterior leg.

Acknowledgements. We want to thank Dr. D. Forsythe, Bielefeld, for proof reading the English manuscript.

\section{References}

Ayers, J.L., Davis, W.J.: Neuronal control of locomotion in the lobster Homarus americanus. II. Types of walking reflexes. J. Comp. Physiol. 115, 29-46 (1977)
Bässler, U.: Zur Beeinflussung der Bewegungsweise eines Beines von Carausius morosus durch Amputation anderer Beine. Kybernetik 10, 110-114 (1972)

Bässler, U.: Reversal of a reflex to a single motoneuron in the stick insect Carausius morosus. Biol. Cybern. 24, 47-49 (1976)

Barnes, W.J.P.: Proprioceptive influence on motor output during walking in the crayfish. J. Physiol. (Paris) 73, 543-564 (1977)

Burrows, M., Hoyle, G.: The mechanism of rapid running in the ghost crab Ocypode ceratophtalma. J. Exp. Biol. 58, 327-349 (1973)

Chasserat, C., Clarac, F.: Interlimb coordinating factors during driven walking in Crustacea. J. Comp. Physiol. 39, 293-306 (1980)

Clarac, F.: Decapod crustacean leg coordination during walking. In: Locomotion and energetics in arthropods, Herreid, C.F., Fourtner, C. (eds.). New York, London: 1981, Plenum Press

Clarac, F., Chasserat, C.: Comparative study of free and driven walking in the rock lobster Jasus lalandii. J. Exp. Biol. (in press)

Clarac, F., Cruse, H.: Comparison of forces developed by the legs of the rock lobster when walking free or on a treadmill. Biol. Cybern. 43, 109-114 (1982)

Clarac, F., Vedel, J.P., Bush, B.M.H.: Intersegmental reflex coordination by a single joint receptor organ (CB) in rock lobster walking legs. J. Exp. Biol. 73, 29-46 (1978)

Cruse, H.: The control of the anterior extreme position of the hindleg of a walking insect, Carausius morosus. Physiol. Entomol. 4, 121-124 (1979)

Cruse, H.: A quantitative model of walking incorporating central and peripheral influences. $\mathrm{I}$. The control of the individual leg. Biol. Cybern. 37, 131-136 (1980a)

Cruse, $\mathrm{H}$.: A quantitative model of walking incorporating central and peripheral influences. II. The connections between different legs. Biol. Cybern. 37, 137-144 (1980b)

Cruse, H., Epstein, S.: Peripheral influences on the movement of the legs in a walking insect (Carausius morosus). J. Exp. Biol. 101, $161-170(1982)$

Cruse, H., Saxler, G.: Oscillations of force in the standing legs of a walking insect (Carausius morosus). Biol. Cybern. 36, 159-163 (1980)

Di Caprio, R.A., Clarac, F.: Reversal of a walking leg reflex elicited by a muscle receptor. J. Exp. Biol. 90, 197-203 (1981)

Graham, D., Cruse, H.: Coordinated walking of stick insect on a mercury surface. J. Exp. Biol. 92, 229-241 (1981)

Grote, J.R.: The effect of load on locomotion in crayfish. J. Exp. Biol, 92, 272-288 (1981)

Hughes, G.M.: Coordination of insect movements. II. The effect of limb amputation and the cutting of commissures in the cockroach. J. Exp. Biol. 34, 306-333 (1957)

Land, M.F.: Stepping movements made by jumping spiders during turns mediated by the lateral eyes. J. Exp. Biol. 57, 15-40 (1972)

MacMillan, D.L.: A physiological analysis of walking in the american lobster (Homarus americanus). Philos. Trans. R. Soc. (London) 270, 1-59 (1975)

Wendler, G.: Laufen und Stehen der Stabheuschrecke Carausius morosus: Sinnesborstenfelder in den Beingelenken als Glieder von Regelkreisen. Z. Vergl. Physiol. 48, 198-250 (1964)

Received: October 26, 1982

Dr. H. Cruse

Fakultät Biologie

Universität Bielefeld

Postfach 8640

D-4800 Bielefeld

Federal Republic of Germany 